Buss-Perry Aggression Questionnaire: Factor Structure and Measurement Invariance among Portuguese Male Perpetrators of Intimate Partner Violence

Olga Cunha $^{\mathrm{a}}$, Manuela Peixoto ${ }^{\mathrm{b}}$, Ana Rita Cruz $^{\mathrm{c}}$, and Rui Abrunhosa Gonçalves ${ }^{\mathrm{d}}$

${ }^{\text {a }}$ Faculty of Psychology, Education, and Sports, Lusófona University of Porto, Porto, Portugal.

${ }^{\mathrm{b}}$ Institute of Psychology and Educational Sciences, Lusíada University of Porto, Portugal.

${ }^{c}$ School of Psychology and Life Sciences, Lusófona University, Lisbon, Portugal.

${ }^{\mathrm{d}}$ School of Psychology, University of Minho, Braga, Portugal.

Correspondence concerning this article should be addressed to Olga Cunha, Faculty of

Psychology, Education, and Sports, Lusófona University of Porto, Rua Augusto Rosa, 24, 4000098, Porto, Portugal.

E-mail address: olga.cunha@ulp.pt

Biographical notes

Olga Cunha, $\mathrm{PhD}$, is an assistant professor at the Faculty of Psychology, Education, and Sports, Lusófona University of Porto, Portugal, and a researcher at the HEI-Lab: Digital HumanEnvironment Interaction Lab.

Manuela Peixoto, $\mathrm{PhD}$, is an assistant professor at the Institute of Psychology and Educational Sciences, Lusíada University of Porto, Portugal, and a researcher at the Psychology for Positive Development Research Center. 
Ana Rita Cruz, PhD, is an assistant professor at School of Psychology and Life Sciences, Lusófona University, Lisbon, Portugal, and a researcher at the HEI-Lab: Digital HumanEnvironment Interaction Lab.

Rui Abrunhosa Gonçalves, $\mathrm{PhD}$, is an associate professor at the School of Psychology, University of Minho, Portugal, and a researcher at Research Center on Psychology (CIPsi).

This study was conducted at Psychology Research Centre (UID/PSI/01662/2013), University of Minho, and supported by the Portuguese Foundation for Science and Technology and the Portuguese Ministry of Science, Technology and Higher Education through national funds and co-financed by FEDER through COMPETE2020 under the PT2020 Partnership Agreement (POCI-01-0145-FEDER-007653). The study was also supported by Grant SFRH/ BD/66110/2009 from the Portuguese Foundation for Science and Technology awarded to the first author.

This article has been accepted for publication in Criminal Justice and Behavior. 


\title{
Buss-Perry Aggression Questionnaire: Factor Structure and Measurement Invariance among Portuguese Male Perpetrators of Intimate Partner Violence
}

\begin{abstract}
The current study aimed to analyze the fit of the four-factor model of the Buss-Perry Aggression Questionnaire (BPAQ) 29-item and the 12-item on a sample of Portuguese male perpetrators of intimate partner violence (IPV; $N=279$ ) and to test the measurement invariance between sample type (forensic and non-forensic) and sentence type (prison and community). Confirmatory factor analysis did not support the four-factor model of the BPAQ 29-item version. The four-factor model of the BPAQ short form (BPAQ-SF) showed a good fit. Sufferable values for internal consistency and good values for convergent and discriminant validity were found. Cross-sentence measurement invariance using the present sample and cross-sample measurement invariance of the BPAQ-SF using a previously collected sample of students was established. Overall, our results support BPAQ-SF as a valuable brief and psychometrically reliable measure of aggression for use with both individuals from the community and IPV perpetrators with different sentences.
\end{abstract}

Keywords: Aggression; Factorial structure; Intimate partner violence; Measurement invariance; Psychometric properties. 
Aggression is considered a personality characteristic of paramount importance for clinical and forensic contexts (i.e., correctional contexts and populations) and research purposes (GallardoPujol et al., 2006; Harris, 1995). One of the most widely accepted definitions in the scientific community is that of Buss (1961), who defines aggression as "a response that delivers noxious stimuli to another organism” (p. 1). This definition was later expanded to include the perpetrator's intent and conceptualizes aggression as any behavior directed toward another person with the intent to cause harm (Anderson \& Bushman, 2002). The term aggression is often used interchangeably with hostility and anger, representing behavioral, cognitive, and emotional components of a more complex concept (e.g., Buss \& Perry, 1992). Physical and verbal aggression represent the instrumental or motor components of behavior. Anger involves physiological arousal and represents the emotional or affective component of the behavior. In addition, hostility consists of feelings of injustice and represents the cognitive component of behavior (Buss \& Perry, 1992).

Aggressiveness influences whether and how an individual behaves violently. Previous studies found that aggression allows differentiation between violent and nonviolent individuals who commit crimes (e.g., Cruz et al., 2019; Helfritz et al., 2006) and is associated with violence persistence (e.g., Serin et al., 2009) and with a greater risk of reoffending (Martin et al., 2019). Hostility and anger have also been associated with violence (Camlibel et al., 2021; Kolla et al., 2016) and reoffending (van der Put et al., 2012). Overall, aggression is a significant risk factor for various forms of antisocial behavior, including intimate partner violence (IPV; e.g., Ruddle et al., 2017; Stith et al., 2004). In general, the findings of various studies supported the theoretical implications of aggression and its sub traits to IPV. Several studies showed a high prevalence of trait aggression among IPV perpetrators (e.g., Archer, 2000; Clements et al., 2018). Literature also showed that IPV perpetrators tend to exhibit higher levels of hostility and anger than nonperpetrators (e.g., Eckhardt et al., 1997; Norlander \& Eckhardt, 2005; Schumacher et al., 2001; 
Stith et al., 2004). Also, anger and hostility are associated with physical violence (Schumacher et al., 2001) and IPV (Birkley \& Eckhardt, 2015; Stith et al., 2004). Notably, anger has been suggested as a trait significantly correlated with IPV perpetration (e.g., Dannisworo et al., 2019; Eckhardt et al., 1997).

Overall, empirical literature suggested that trait aggressiveness is related to IPV offending and IPV reoffending. Thus, accurate assessment of this construct using valid instruments is essential to understanding IPV and to develop practical assessment and treatment and prevention strategies for IPV perpetrators (e.g., Birkley \& Eckhardt, 2015; Norlander \& Eckhardt, 2005).

\section{The Buss-Perry Aggression Questionnaire (BPAQ)}

Buss and Perry (1992) developed and tested the Aggression Questionnaire (BPAQ) in a sample of 1253 college students in introductory psychology courses. BPAQ consists of 29-items and aims to assess four major aspects of aggression: Physical Aggression, Verbal Aggression, Anger, and Hostility (Buss \& Perry, 1992). In the original version, the Confirmatory Factor Analysis (CFA) revealed a good fit of the four-factor model and adequate reliability for the four subscales and the total score (Buss \& Perry, 1992). The BPAQ has been translated and validated in several languages, such as Greek (Vitoratou et al., 2009), Turkish (Demirtas-Madran, 2012), Dutch (Hornsveld et al., 2009), Spanish (Morales-Vives et al., 2005), Japanese (Nakano, 2001; Ramirez et al., 2001), Chinese (Maxwell, 2007), Italian (Fossati et al., 2003), Swedish (Prochazka \& Agren, 2001), European Portuguese (Cunha \& Gonçalves, 2012; Simões, 1993), and others.

Several studies have examined the factorial structure of BPAQ among non-forensic samples (e.g., Cunha \& Gonçalves, 2012; Demirtas-Madran, 2012; Fossatti et al., 2003; Morales-Vives et al., 2005; Ramirez et al., 2001; Simões, 1993). However, despite its widespread use, some doubts remain regarding BPAQ's structure and its applicability (e.g., Bryant \& Smith, 2001). Some studies reported a poor fit of the four-factor structure (e.g., Archer et al.,1995; Harris, 1997; Maxwell, 
2007), while others achieved a good fit only after removing some items (e.g., Harris, 1995; Nakano, 2001). After analyzing variants of the four-factor model proposed by Buss and Perry (1992), Bryant and Smith (2001) developed a better-adjusted model. The authors removed items that loaded lower than .40 , loaded on more than one factor equal to or higher than .40 , or whose content did not appear to reflect aggression directly. The resulting short version of the BPAQ (BPAQ-SF) consisted of 12 items, providing a good fit to the four-factor model, explained an acceptable amount of variance, and revealed convergent and discriminant validity. These results have been replicated in various contexts (e.g., Gallardo-Pujol et al., 2006; Hornsveld et al., 2009; Maxwell, 2007; Morales-Vives et al., 2005; Pechorro et al., 2015; Vitoratou et al., 2009).

Few studies have examined the psychometric properties of the BPAQ in populations of adult individuals who commit crimes, and the most part only achieved a good fit with the 12-item version. Williams and colleagues (1996) examined the BPAQ four-factor model in forensic samples and found a poor fit. The authors then conducted statistical analyses and proposed a twofactor model: one factor combined Physical Aggression and Anger, and the other factor combined Verbal Aggression and Hostility (Williams et al., 1996). Diamond et al. (2005) tested seven models of the BPAQ and BPAQ-SF in a forensic sample of mentally disordered male individuals. They achieved a good fit only for the BPAQ-SF four-factor model. Similar results were found with samples of violent forensic psychiatric inpatients and outpatients (Hornsveld et al., 2009) and violent individuals (Pettersen et al., 2018). Cross-validation studies also supported Diamond et al.'s model (2005), which was subsequently replicated by Diamond and Magaletta (2006). Curiously, Redondo et al. (2017) found support for the four-factor structure in a Spanish sample of IPV perpetrators undergoing psychological treatment. However, Pettersen et al. (2016) found no support for the four-factor structure of the 29-item or the 12-item BPAQ in a sample of incarcerated individuals who had committed sexual offenses. 
BPAQ and its short form are commonly used in forensic settings (Diamond et al., 2005) and have demonstrated value in predicting general violent behavior in adults (e.g., Camlibel et al., 2021; Diamond et al., 2005; Diamond \& Magaletta, 2006) and adolescents (e.g., Pechorro et al., 2016). However, several international studies showed that the original 29-item structure of the BPAQ did not yield an acceptable fit among forensic populations (e.g., Hornsveld et al., 2009; Pettersen et al., 2016, 2018; Williams et al., 1996) and only the 12-item version achieved an acceptable fit (e.g., Diamond \& Magaletta, 2006). Furthermore, and although literature suggests an association between aggression and IPV perpetration (e.g., Ruddle et al., 2017), little is known about the usefulness and validity of the BPAQ and its reduced version among IPV populations. To our knowledge, only one study examined the 29-item BPAQ factorial structure among IPV perpetrators (Redondo et al., 2017), and none have analyzed the BPAQ-SF in this population. In Portugal, BPAQ, especially the 29-item version, is also commonly used to measure aggression in individuals who commit different types of violent crimes, including IPV perpetrators (e.g., Agulhas \& Anciães, 2015; Gonçalves et al., 2011). However, no studies examined the psychometric properties of the BPAQ, both the 29-item and 12-item versions, among IPV perpetrators or other adult forensic populations. Thus, in the present study, we aimed to analyze the factorial structure of the BPAQ original version (Buss \& Perry, 1992) and the BPAQ-SF (Bryant \& Smith, 2001) in a forensic sample of Portuguese IPV perpetrators. In addition, we aimed to test the measurement invariance between sample setting and sentence type. Moreover, we assessed the convergent validity by testing the relationship between the BPAQ factors and other variables, such as psychopathological dimensions and the frequency of physical and psychological violence in intimacy. By doing so, we hope to obtain a valid, reliable, and valuable instrument to assess aggression and its sub traits among IPV perpetrators.

\section{Method}




\section{Participants}

The study integrated data from two samples: a previously collected non-forensic sample (Cunha \& Gonçalves, 2012) and a forensic sample of IPV perpetrators. The forensic sample was recruited from eight national prisons, probation services, child protection services, and family services. The institutions were selected based on a) geographic location and b) users/inmates characteristics (i.e., convicted perpetrators of IPV). Participants were selected using the following inclusion criteria: a) being male; b) being older than 18 years old; c) being involved in a heterosexual intimate relationship; d) being convicted for IPV; e) speaking Portuguese; and f) having sufficient intellectual and communication skills to respond to the instruments used. Participants recruited from child protection services were men whose children were referred to the system for exposure to IPV and/or child maltreatment. Men recruited from family services received family support and/or parental counseling after exposing their children to IPV.

The forensic sample included 279 men convicted of crimes against an intimate partner. Of these, $141(50.5 \%)$ were in prison, and $138(49.5 \%)$ had community orders (i.e., suspended prison sentences, provisional suspension processes). Participants had a mean age of $44.29(S D=$ 11.31), ranging from 22 to 81 years old. Nearly half of the participants were married $(n=118$, $42.3 \%)$ and were of middle to low socioeconomic status $(n=131,47.1 \%)$. More than half of the participants had between four and six years of education $(n=190,68.1 \%)$. Detailed sociodemographic characteristics are presented in Table 1.

The community sample was recruited among undergraduate students using convenience sampling. This sample consisted of 633 participants, with a mean age of $21.64(S D=4.68)$, ranging from 17 to 53 years, and was used in a previous study (Cunha \& Gonçalves, 2012). Most of the participants were female $(n=402,63.5 \%)$ and attended the first $(n=150,23.7 \%)$ and 
second $(n=231,36.5 \%)$ year of undergraduate school. The community sample was used only to test the measurement invariance.

\section{Procedures}

For collecting the forensic sample, various services in charge of assessing/intervening with individuals who commit crimes (e.g., correctional facilities, probation services, child protection services, family services) were contacted. Authorization to access the institutionalized individuals was obtained from the General Directorate of Reintegration and Prison ServicesMinistry of Justice (DGRSP-MJ). Through dialogue with the professionals who worked with the participants and through their files' analysis, we were able to identify the men who fulfilled the previously mentioned inclusion criteria. Then, participants were contacted by a researcher, received a proper explanation of the procedures, and consent to participate in the present study was obtained through the collection of a signed consent form. Self-report measures were completed individually in an appropriate setting: institutionalized individuals completed the instruments in a private room inside the prison; individuals in the community completed the instruments in a private room in the institutions mentioned above. Participation in the study was anonymous (i.e., no personal information was collected) and voluntary (i.e., no compensation was provided for participation).

The non-forensic sample was recruited for a previous study among undergraduate students from various courses (e.g., Humanities and Sciences fields). Written informed consent was obtained from each participant, with information regarding the objectives and anonymous nature of the study. The measure was administered collectively in the classroom (for more details on sampling procedures see Cunha \& Gonçalves, 2012). 
This study was conducted between 2012 and 2019. All ethical procedures established by Portuguese legislation were accomplished, and the ethical approval was granted by the Ethics Committee of the University of Minho.

\section{Measures}

Sociodemographic characteristics were evaluated through several questions developed for this study. Questions about age, education level, marital status, and socioeconomic status (SES) were assessed. SES was determined based on Graffar's (1956) classification. For the forensic sample, information regarding the legal process was collected through individual file consultation.

The Buss-Perry Aggression Questionnaire (BPAQ; Buss \& Perry, 1992) is a self-report instrument consisting of 29 items, answered on a 5-point Likert scale, ranging from 1 (extremely uncharacteristic of me) to 5 (extremely characteristic of me). The BPAQ assesses four dimensions of aggression: 1) Physical Aggression (nine items); 2) Verbal Aggression (five items); 3) Anger (seven items); and 4) Hostility (eight items). The original version showed good psychometric properties, with internal consistency values ranging from .72 to .85 for the four subscales and .89 for the total scale (Buss \& Perry, 1992). The Portuguese version of the BPAQ (Cunha \& Gonçalves, 2012) achieved a Cronbach's alpha of .88 for the total scale, .56 for the Verbal Aggression, .76 for Physical Aggression, .79 for Anger, and .76 for Hostility. The BussPerry Aggression Questionnaire-Short Form (BPAQ-SF; Bryant \& Smith, 2001) is a short version of the BPAQ and consists of 12 items organized into four scales of three items each: Physical Aggression, Verbal Aggression, Anger, and Hostility. Bryant \& Smith (2001) changed the original 5 point-scale to a 6-point scale to eliminate the midpoint. Our version consisted of a 5-point Likert scale, restoring the scale's midpoint and maintaining the original rating scale. This modification was based on Gallardo-Pujol et al. (2006) criteria: a) five response alternatives seem 
to be more appropriate in the context of cross-cultural comparisons; b) empirical studies supported the traditional 5-point Likert format; c) the variability of a personality measure does not change significantly when a response category is reduced; c) the BPAQ original version has a 5-point scale.

The Brief Symptoms Inventory (BSI; Derogatis, 1993) is a self-report measure consisting of 53 items, answered on a 5-point Likert scale, from 1 (never) to 5 (many times), that assess psychopathological symptoms. The inventory assesses nine dimensions of psychopathology (Somatization, Obsession-Compulsion, Interpersonal Sensibility, Depression, Anxiety, Hostility, Phobic Anxiety, Paranoid Ideation, and Psychoticism), and three global indexes of distress: Global Severity Index (GSI), Positive Symptom Distress Index (PSI) and Positive Symptom Total (PST). The original version showed good psychometric properties, with Cronbach's alpha ranging from .71 (Psychoticism) to .85 (Depression). The Portuguese version of the BSI (Canavarro, 2007) also showed adequate internal consistency, with Cronbach's alpha ranging from .62 to .80 . In the present study, the dimensions of Anxiety, Hostility, and Paranoid Ideation were used. The Cronbach's alphas found were .77 for Anxiety, .73 for Hostility, and .66 for Paranoid Ideation for the present forensic sample.

The Marital Violence Inventory (IVC; Machado et al., 2007) is a self-report measure that includes 21 items, answered on a 3-point scale ( 0 - never, 1 - once, 2 - more than once), and captures two core dimensions: Physical Violence and Psychological Violence. Previous studies reported good internal consistency values, with Cronbach alpha values ranging from .81 to .85 for Physical Violence, ranging from .51 to .72 for Psychological Violence, and ranging from .80 to .83 for the total scale (Cunha \& Gonçalves, 2015; 2016). In the current study, Cronbach's alpha values were .83 for Physical Violence, .63 for Psychological Violence, and .84 for total score in the forensic sample. 


\section{Data analysis}

Descriptive statistics were used to characterize the sample. Confirmatory Factor Analysis (CFA) using the software AMOS 27 (Arbuckle, 2017) were conducted to determine which BPAQ version was a better fit for the data. Two versions were tested: a) the original four-factor model (Buss \& Perry, 1992); b) and the short version of the four-factor model (Bryant \& Smith, 2001). The adjustment quality of the BPAQ versions was assessed using the following indexes: a) $x^{2} / d f$ (the ratio between chi-square and degrees of freedom) inferior to 2.0; b) TLI (Tucker-Lewis Index) and CFI (Comparative Fit Index) superior to .90; c) RMSEA (Root Mean Square Error of Approximation) inferior to 0.10; d) AIC (Akaike Information Criterion) which has no reference value, but the lower, the better (Marôco, 2014). Then, the retaining BPAQ version (i.e., those revealing better fit to the data) was subject to different analyses. The invariance of the factorial model across sample type (forensic vs. non-forensic sample) and type of sentence (prison vs. community orders) was assessed through a Multigroup Confirmatory Factor Analysis (MCFA). Measurement invariance was analyzed through configural (structure equivalence), metric (factor loadings equivalence), and scalar invariance (intercept equivalence; Horn \& McArdle, 1992). The chi-square difference test $\left(\Delta \chi^{2}\right)$, and the Comparative Fit Index difference test $(\Delta \mathrm{CFI}$; Cheung \& Rensvold, 2002) were analyzed to assess the instrument invariance. Because the $\Delta \mathrm{x}^{2}$ is sensitive to sample size, some authors have questioned its use in large or heterogeneous samples (Marôco, 2014). The $\Delta$ CFI was used to overtake this limitation since it is not affected by the model specification (Cheung \& Rensvold, 2002). To assume the measurement invariance, the $\Delta C F I$ value should be smaller or equal to 0.01 (Cheung \& Rensvold, 2002).

The convergent validity was tested using the Pearson correlation coefficient between BPAQ factors and the IVC total score and the Physical and Psychological subscales and the BSI Anxiety, Hostility, and Paranoid Ideation dimensions. In addition, we analyzed correlations 
between factors to test the discriminant validity of the BPAQ factors. Values lower than .85 are indicators of discriminant validity (cf. Netemeyer et al., 2003). Construct validity was also assessed through the Extracted Average Variance (VME; $\geq 0.5 \mathrm{cf}$. Netemeyer et al., 2003) and Composite Reliability (CR; $\geq 0.7$ cf. Hair et al., 2010; Netemeyer et al., 2003). The internal consistency was calculated to analyze the psychometric properties of the instrument, through the Cronbach's Alpha ( $\geq .070$; cf. Field, 2017) and the mean inter-item correlation (values ranging between .15-.50, cf. Domino \& Domino, 2006). Finally, to examine differences between samples (i.e., forensic vs. non-forensic; prison vs. community orders) ANCOVA tests were performed. All procedures were performed on data analysis software IBM SPSS 27.

\section{Results}

\section{Descriptive analysis}

Table 2 shows the mean, standard deviation, and range of BPAQ original (29 items) and BPAQ-SF (12 items), BSI Anxiety, Hostility, and Paranoid Ideations domains, and IVC for IPV perpetrators' sample.

\section{INSERT HERE TABLE 2}

\section{Confirmatory factor analysis}

Confirmatory Factor Analysis (CFA) was used to test the two-factor structures of the BPAQ in the forensic sample: the original Buss and Perry (1992) structure (29 items) and the Bryant and Smith (2001) version (12 items). Multivariate distribution was confirmed for all the 12 items in the BPAQ-SF. In the 29 BPAQ version, three items (items 1, 10, and 29) had skewness higher than 3 and kurtosis higher than 7. However, these items were not excluded to assess the construct validity of the Portuguese version of the 29 items questionnaire.

Based on the analysis of the goodness of fit indices the BPAQ-SF (12 items) was the best fitting model among the forensic sample (cf. Table 3$): x^{2} / \mathrm{df}=3.653, \mathrm{CFI}=.93, \mathrm{NFI}=.98$, 
RMSEA $=.065$. Standardized factor loadings and item-total Pearson correlations of the BPAQSF four-factor model are reported in Table 4. All the items' factor loadings, except for item 6 (.48), were higher than .50 (Marôco, 2014).

\section{INSERT HERE TABLE 3}

INSERT HERE TABLE 4

\section{Convergent and discriminant validity}

The BPAQ-SF's factors in the forensic sample (Table 5) were all positively intercorrelated. The most expressive values were between Anger and Physical Aggression (.472), between Anger and Verbal Aggression (.471), and between Anger and Hostility (.421). All the correlations were lower than .85 (cf. Netemeyer et al., 2003), revealing discriminant validity. The Average Variance Extracted (AVE) and the Composite Reliability (CR) of each factor were estimated to better explore the construct validity. The AVE was only satisfactory for factor 1 $(.50 ; \geq 0.5$ cf. Netemeyer et al., 2003). The values for factors 2,3 , and 4 were $.33, .39$, and .45 , respectively. The elimination of items with factor loadings lower than .50 (item 6) did not lead to AVE satisfactory values. The CR (i.e., an internal consistency measure; Hair et al., 2010) was above the recommended values for factor $1(.74)$ and for factor $4(.71)$ and below the recommended values for factor 2 (.60) and factor $3(.66 ; \geq 0.7$; cf. Hair et al., 2010; Netemeyer et al., 2003).

\section{INSERT HERE TABLE 5}

The results of the IVC total score, the IVC Physical and the Psychological subscales, and the BSI Anxiety, Hostility, and Paranoid Ideation domains in the forensic sample were also used to assess convergent validity. Correlation analysis between the subscales of the BPAQ-SF and the other variables (see Table 5) revealed significant positive correlations between all the subscales of the BPAQ-SF and the BSI domains, between almost all the BPAQ-SF subscales and the IVC 
total scale and the IVC subscales, except between Verbal Aggression and the IVC subscales and the IVC total scale and between Anger and IVC Physical Violence subscale. The highest correlations were observed between BSI Anxiety domain and Anger subscale $(r=.41, p<.001)$, Hostility subscale $(r=.45, p<.001)$ and BPAQ-SF total scale $(r=.46, p<.001)$, between Hostility domain and Physical Aggression subscale $(r=.46, p<.001)$, Verbal Aggression subscale $(r=.42, p<.001)$, Anger subscale $(r=.56, p<.001)$ and BPAQ-SF total scale $(r=.60$, $p<.001)$, and between BSI Paranoid Ideation domain and Hostility subscale $(r=.43, p<.001)$.

\section{Internal consistency}

In the internal consistency analysis of the BPAQ-SF, the values of Cronbach's alphas were weak (Field, 2017): .53 for Verbal Aggression, .55 for Anger, .56 for Hostility and .57 for Physical Aggression. The Cronbach's alpha for the BPAQ-SF total scale was acceptable (.78). However, based on mean inter-item correlations, the BPAQ-SF total scale and all four subscales showed good internal consistency (within the recommended value range of .15-.50; Domino \& Domino, 2006).

\section{Invariance of the factor structure between samples}

Measurement invariance was tested across sample type and sentence type using the BPAQ-SF (Table 6). The factorial model showed a good fit to the forensic and non-forensic samples simultaneously, $x^{2} / \mathrm{df}=2.352 ; \mathrm{RMSEA}=.039 ; \mathrm{CFI}=.95 ; \mathrm{TLI}=.93$, revealing configural invariance. The $\Delta x^{2}$ and the $\Delta$ CFI showed metric, $\Delta x^{2}(8)=16.526, p=.035$, and scalar invariance, $\Delta \chi^{2}(18)=31.598, p=.025$. Similarly, the four-factor model revealed an acceptable fit, $\mathrm{x}^{2} / \mathrm{df}=1.351 ; \mathrm{RMSEA}=.036 ; \mathrm{CFI}=.95 ; \mathrm{TLI}=.92$, to the perpetrators in prison and those with community orders, showing configural invariance. Results also revealed metric, $\Delta \chi^{2}(8)=17.161, p=.028$, and scalar invariance, $\Delta \chi^{2}(18)=37.284, p=.005$. These overall results confirm the presence of measurement invariance across sample type. 


\section{INSERT HERE TABLE 6}

\section{Comparisons between groups}

IPV perpetrators were compared with individuals from the community (non-forensic), and IPV perpetrators sentenced to prison were compared with IPV perpetrators sentenced with community orders. To compare IPV perpetrators with community individuals, age was corrected by including this variable as a covariate in the analysis of variance, as the community sample was significantly younger than the forensic sample (Table 7). Results showed that IPV perpetrators scored significantly higher on the Physical Aggression and Hostility scales than individuals from the community. Individuals from the community scored significantly higher than IPV perpetrators on BPAQ-SF total scale, Verbal Aggression and Anger scales. No differences were found between IPV perpetrators with prison sentences and community orders.

\section{INSERT HERE TABLE 7}

\section{Discussion}

The BPAQ (Buss \& Perry, 1992) is a self-report measure used worldwide to assess four clusters of aggression: Physical Aggression, Verbal Aggression, Anger, and Hostility. However, the BPAQ four-factor model showed a poor fit with forensic samples. Therefore, the BPAQ-SF was tested and received empirical support for forensic samples. Since aggression and its sub traits are significantly associated with IPV perpetration (e.g., Dannisworo et al., 2019; Schumacher et al., 2001; Stith et al., 2004), there is a need for reliable instruments to assess aggression in partner-violent men. Therefore, the current study aimed to analyze the factorial structure of the original and short versions of the BPAQ in a Portuguese sample of IPV perpetrators.

Confirmatory factor analyses did not support the original BPAQ four-factor structure, which was somewhat expected since some items showed a non-normal distribution. In agreement, previous studies with forensic samples did not yield a good fit for the original four- 
factor structure (e.g., Diamond et al., 2005; Diamond \& Magaletta, 2006; Hornsveld et al., 2009; Pettersen et al., 2018). However, the BPAQ-SF revealed a good model fit, supporting the fourfactor model proposed by Bryant and Smith (2001). All goodness of fit indices revealed better values for the SF than for the original version, which is also consistent with previous data (e.g., Diamond et al., 2005; Diamond \& Magaletta, 2006; Hornsveld et al., 2009; Pettersen et al., 2018). Tests of measurement invariance confirmed the factor structure across sample type and sentence type. This finding is relevant as it gives researchers and clinicians more confidence in generalizing results across groups. Nevertheless, testing the measurement invariance of the BPAQ-SF across other groups (e.g., age, ethnicity) is needed. Our results suggest that, within the Portuguese context, the BPAQ-SF is superior to the BPAQ in populations of IPV perpetrators. However, further investigations of the test-retest stability are recommended.

Regarding discriminant validity, the BPAQ-SF four subscales showed a positive intercorrelation, as other studies with forensic samples (e.g., Diamond \& Magaletta, 2006). This result is expected as each factor is a specific dimension that constitutes the aggression construct. Results suggested a fair amount of discriminative ability among those subscales, meaning each factor captures a different feature of the aggression construct. As Diamond and Magaletta (2004, p. 235) stated, "for a short scale with correlated factors, this is promising".

Convergent validity was assessed by correlating the BPAQ-SF scales with other external variables, specifically the Physical Violence and Psychological Violence subscales of the IVC, the IVC total scale, and the BSI Anxiety, Hostility, and Paranoid Ideation domains. As expected, significant and positive correlations were found between those external variables, which is consistent with the findings of previous studies (e.g., Redondo et al., 2017; Valdivia-Peralta et al., 2014). The BPAQ-SF Anger scale was also positively and significantly correlated with the IVC Psychological Violence and the IVC total scale. These results follow previous research 
linking aggression and its sub traits - anger and hostility - with IPV perpetration (e.g., Birkley \& Eckhardt, 2015; Norlander \& Eckhardt, 2005). Nonetheless, BPAQ-SF Anger scale was not correlated with IVC Physical Violence scale, and BPAQ-SF Verbal Aggression scale did not reveal significant correlations with any of the IVC scales. There are several possible explanations for these results. First, and as further explained, Anger and Verbal Aggression scales had the lowest Cronbach's alphas, which may explain the absence of correlations between these factors and other external variables. Another explanation may be that BPAQ-SF Verbal Aggression and Anger scales assess verbal aggressive tendencies and physiological arousal and preparation for aggression, respectively, rather than behavioral manifestations. Previous reviews point to inconsistent findings regarding the relationship between anger and IPV, explaining the absence of a relationship between Anger and Verbal Aggression and IVC scales. It seems to vary under the construct assessed and the assessment strategy used (Eckhardt et al., 1997). However, further studies are recommended to support these explanations.

Regarding BSI domains, as expected, all the BSI domains revealed significant and positive correlations with all subscales of the BPAQ-SF. BPAQ-SF Hostility and Anger were the scales that showed the strongest correlations with the BSI domains, which is consistent with the definitions of each domain. For example, the BSI Hostility domain includes thoughts, emotions, and behaviors characteristic of the cholera state; the BSI Paranoid Ideation domain includes the projective thought, hostility, and suspicion (Derogatis, 1993). These results are consistent with previous studies that reported significant associations between BPAQ Hostility subscale and mental health problems (e.g., Diamond \& Magaletta, 2006). Positive associations between aggression sub traits and anxiety (e.g., Chung et al., 2019), hostility (e.g., Rubio-Garay et al., 2016), and paranoid ideation (e.g., Coid et al., 2016; Diamond \& Magaletta, 2006) have also been 
found in the literature. Correlations between the BPAQ-SF scales and other measures provide evidence for the convergent validity of the BPAQ-SF.

Regarding the internal consistency, the Cronbach's alphas were unsatisfactory and significantly lower than those reported by other studies (e.g., Diamond et al., 2005; GallardoPajol et al., 2006; Hornsveld et al., 2009; Pettersen et al., 2016; Smith \& Briant, 2001). Nevertheless, it is noteworthy that Cronbach's alpha is sensitive to the number of items by scale (Field, 2017), and BPAQ-SF only has three items by scale. Some studies also found low alpha values in some scales (Morren \& Meesters, 2002; Ramirez et al., 2001) including the Portuguese version of BPAQ-SF for adolescents (Pechorro et al., 2016). For this reason, we calculated the mean inter-item correlations (which is a straightforward measure of internal consistency), and values were within the recommended range of .15-.50 (Domino \& Domino, 2006).

Comparative analysis between the groups (i.e., IPV perpetrators vs. community; prison sentences vs. community sentences) revealed that IPV perpetrators scored higher on Physical Aggression and Hostility scales. These results follow previous results that reported higher levels of physical aggression and hostility among IPV perpetrators (e.g., Birkley \& Eckhardt, 2015; Norlander \& Eckhardt, 2005). However, contrary to our expectations, individuals from the community scored higher on BPAQ-SF total scale and Anger and Verbal Aggression scales. One possible explanation for this result is that IPV perpetrators completed the questionnaire in a more socially desirable manner to avoid negative clinical and legal consequences (Hornsveld et al., 2009). Indeed, when measuring self-reported aggression, social desirability may represent response bias (Harris, 1997). This is relevant as the literature suggests that reports of IPV perpetrators may be influenced by social desirability (Helfritz et al., 2006). Although these results were somewhat unexpected, previous literature regarding anger and IPV is inconsistent (Eckhardt et al., 1997). The same is true when comparing IPV perpetrators sentenced to prison and those 
with community measures since no differences were found between the two groups. Although some research points to a more psychopathological profile with higher levels of anger among institutionalized IPV perpetrators (e.g., Fernandez-Montalvo et al., 2013; Garcia-Jimenez et al., 2014), others found that the factors related to the severity of violence were those that differentiate individuals in prison from those with community orders (e.g., Cunha \& Gonçalves, 2017).

Despite the current findings, some limitations should be acknowledged. First, the mean age of the non-forensic sample was lower than that of the forensic sample, and the educational level was lower in the forensic sample. These differences may affect our findings (e.g., instrument validity; differences between forensic and non-forensic samples) since, for example, participants' education level and/or reading level may compromise their ability to fully understand the BPAQ items. However, because participants from the forensic sample completed the questionnaires individually, they also had more opportunities to clarify doubts about the interpretation of the items. Second, our samples were collected using convenience methods (both in terms of participants and institutions), which limits the generalizability of the current findings. Third, this is a cross-sectional study, and longitudinal analyses are needed to test the BPAQ-SF invariance and predictive utility. Fourth, the forensic sample consisted entirely of men, and the vast majority was Caucasian. Future studies on BPAQ factor structure should include a more ethnically diverse sample as well as include women. Fifth, there is the possibility of bias in IPV perpetrators' responses to the questionnaire; specifically, the reports of IPV perpetrators may be influenced by image manipulation and social desirability (Helfritz et al., 2006).

Although some caveats results from this study point toward the utility of the BPAQ-SF among forensic populations, namely IPV perpetrators. The existence of a short, rapidly applicable, and reliable self-report measure would help professionals who work in the forensic context, and especially those who work with IPV perpetrators, for several reasons. First, 
individuals in this context often exhibit characteristics that limit the use of longer measures (e.g., reading limitations, time constraints, resistance; Gallardo-Pujol et al., 2006); hence the existence of a short questionnaire might allow overcoming these limitations. Second, since BPAQ-SF is a valid tool to assess aggressive tendencies, it could help professionals make more appropriate decisions about individuals' management, assignment to treatment, and evaluation of treatment effectiveness (Diamond et al., 2005; Diamond \& Magaletta, 2006). Finally, because IPV is a public health concern, affecting men and women worldwide, the existence of empirically validated self-report measures assessing psychological dimensions related to IPV, could help develop more appropriate prevention and intervention programs for this specific population. It also provides a reliable measure to better understand the perpetrator's profile, allowing professionals to address specific characteristics in prevention programs for IPV.

Overall, our findings provide additional support for the BPAQ-SF four-factor model of aggression among IPV perpetrators reinforcing its potential application across different cultural backgrounds and languages. Despite some limitations, the BPAQ-SF demonstrated good psychometric properties that justify its use among Portuguese IPV perpetrators, either in the context of forensic assessments or in the context of individuals management and treatment. 


\section{References}

Agulhas, R., \& Anciães, A. (2015). Casos práticos em psicologia forense: Enquadramento legal e avaliação pericial [Case studies in forensic psychology: Legal framework and expert assessment] (2nd ed.). Edições Sílabo.

Anderson, C., \& Bushman, B. (2002). Human aggression. Annual Review of Psychology, 53, 27-51. https://doi.org/10.1146/annurev.psych.53.100901.135231

Arbuckle, J. L. (2017). IBM SPSS AMOS 25 User's guide. IBM SPSS.

Archer, J. (2000). Sex differences in aggression between heterosexual partners: A meta-analytic review. Psychological Bulletin, 126(5), 651-680. https://doi.org/10.1037/0033$\underline{2909.126 .5 .651}$

Archer, J., Kilpatrick, G., \& Bramwell, R. (1995). Comparison of two aggression inventories. Aggressive Behavior, 21(5), 371-380. https://doi.org/10.1002/10982337(1995)21:5<371::AID-AB2480210506>3.0.CO;2-P

Birkley, E., \& Eckhardt, C. (2015). Anger, hostility, internalizing negative emotions, and intimate partner violence perpetration: A meta-analytic review. Clinical Psychology Review, 37, 40-56. https://doi.org/10.1016/j.cpr.2015.01.002

Bryant, F. B., \& Smith, B. D. (2001). Refining the architecture of aggression: A measurement model for the Buss-Perry Questionnaire. Journal of Research in Personality, 35(2), 138167. https://doi.org/10.1006/jrpe.2000.2302

Buss, A. (1961). The psychology of aggression. John Wiley \& Sons, Inc.

Buss, A. H., \& Perry, M. (1992). The Aggression Questionnaire. Journal of Personality and Social Psychology, 63(3), 452-459. https://doi.org/10.1037/0022-3514.63.3.452 
Camlibel, D. A., Can, S. H., \& Hendy, H. M. (2021). Predictors of violence reported by female and male inmates in Wisconsin state prisons. Women \& Criminal Justice. Published online, 1-13. https://doi.org/10.1080/08974454.2021.1892565

Canavarro, M. C. (2007). Inventário de Sintomas Psicopatológicos: Uma Revisão crítica dos estudos realizados em Portugal [Brief Symptom Inventory: A critical revision of the studies conducted in Portugal]. In L. Almeida, M. Simões, C. Machado, \& M. Goncalves (Eds.), Avaliação psicológica. Instrumentos validados para a população portuguesa [Psychological assessment: Validated instruments for the portuguese population] (Vol. III, pp. 305-331). Quarteto Editora.

Cheung, G. W., \& Rensvold, R. B. (2002). Evaluating goodness-of-fit indexes for testing measurement invariance. Structural Equation Modeling, 9(2), 233-255. https://doi.org/10.1207/S15328007SEM0902_5

Chung, J. E., Song, G., Kim, K., Yee, J., Kim, J. H., Lee, K. E., \& Gwak, H. S. (2019). Association between anxiety and aggression in adolescents: A cross-sectional study. $B M C$ Pediatrics, 115. https://doi.org/10.1186/s12887-019-1479-6

Clements, C. M., Clauss, K., Casanave, K., \& Laajala, A. (2018) Aggression, Psychopathology, and Intimate Partner Violence Perpetration: Does Gender Matter? Journal of Aggression, Maltreatment \& Trauma, 27(8), 902-921. https://doi.org/10.1080/10926771.2017.1410750

Coid, J., Ullrich, S., Bebbington, P., Fazel, S., \& Keers, R. (2016). Paranoid ideation and violence: Meta-analysis of individual subject data of 7 population surveys. Schizophrenia Bulletin, 42(4), 907-915. https://doi.org/10.1093/schbul/sbw006

Cruz, A. R., Castro-Rodrigues, A., Rundle, B., Berrios-Torres, I., Gonçalves, R. A., Barbosa, F., \& Stanford, M. S. (2019). Versatility and exploratory psychometric properties of the 
impulsive/premeditated aggression scale (IPAS): A review. Aggression and Violent Behavior, 47, 12-20. https://doi.org/10.1016/j.avb.2019.03.003

Cunha, O., \& Gonçalves, R. (2012). Análise confirmatória fatorial de uma versão portuguesa do Questionário de Agressividade de Buss-Perry [Confirmatory factor analysis of a Portuguese version of the Buss-Perry Aggression Questionnaire]. Laboratório de Psicologia, 10(1), 3-17.

Cunha, O., \& Goncalves, R. A. (2015). Efficacy assessment of an intervention program with batterers. Small Group Research, 46(4), 455-482. https://doi.org/10.1177/1046496415592478

Cunha, O., \& Goncalves, R. A. (2016). Severe and less severe intimate partner violence: From characterization to prediction. Violence and Victims, 31(2), 235-250. https://doi.org/10.1891/0886-6708.VV-D-14-00033

Cunha, O., \& Gonçalves, R. A. (2017). Male perpetrators of intimate partner violence: A comparison between incarcerated and community offenders. International Journal of Offender Therapy and Comparative Criminology, 62(11), 3260-3277. https://doi.org/10.1177/0306624X17741070

Dannisworo, C. A., Adiningsih, H. B., \& Christia, M. (2019). The moderating role of trait anger in the relationship between masculine stress and intimate partner violence. Psychological Research on Urban Society, 2(2), 106-117. https://doi.org/10.7454/proust.v2i1.71

Demirtas-Madran, H. A. (2012). The reliability and validity of the Buss-Perry aggression questionnaire (BAQ) - Turkish version. Turkish Journal of Psychiatry, 24(2), 124-129.

Derogatis, L. R. (1993). BSI: Brief Symptom Inventory: Administration, scoring and procedures manual. Natural Computers System. 
Diamond, P. M., \& Magaletta, P. R. (2006). The Short-Form Buss-Perry Aggression

Questionnaire (BPAQ-SF): A validation study with federal offenders. Assessment, 13(3), 227-240. https://doi.org/10.1177/1073191106287666

Diamond, P. M., Wang, E. W., \& Buffington-Vollum, J. (2005). Factor structure of the BussPerry Aggression Questionnaire (BPAQ) with mentally ill prisoners. Criminal Justice and Behavior, 32(5), 546-564. https://doi.org/10.1177/0093854805278416

Domino, G., \& Domino, M. (2006). Psychological testing: An introduction (2nd ed.). Cambridge University Press.

Eckhardt, C. I., Barbour, K. A., \& Stuart, G. L. (1997). Anger and hostility in maritally violent men: Conceptual distinctions, measurement issues, and literature review. Clinical Psychology Review, 17(4), 333-358. https://doi.org/10.1016/s0272-7358(96)00003-7

Fernandez-Montalvo, J., Echauri, J. A., \& Martinez Azcarate, J. M. (2013). Batterer men in prison and in court-referred treatment programs: What is the difference? The Spanish Journal of Psychology, 15(1), 315-322. https://doi.org/10.5209/rev_SJOP.2012.v15.n1.37338

Field, A. (2017). Discovering statistics using IBM SPSS statistics (5th Ed.). Sage.

Fossati, A., Maffei, C., Acquarini, E., \& Di Ceglie, A. (2003). Multigroup confirmatory component and factor analyses of the Italian version of the Aggression Questionnaire. European Journal of Psychological Assessment, 19(1), 54-65. https://doi.org/10.1027//1015-5759.19.1.54

Gallardo-Pujol, D., Kramp, U., García-Forero, C., Pérez-Ramírez, M., \& Andrés-Pueyo, A. (2006). Assessing aggressiveness quickly and efficiently: The Spanish adaptation of Aggression Questionnaire-Refined version. European Psychiatry, 21(7), 487-494. https://doi.org/10.1016/j.eurpsy.2006.02.002 
Garcia-Jimenez, J. J., Godoy-Fernandez, C., Llor-Esteban, B., \& Ruiz-Hernandez, A. (2014). Differential profile in partner aggressors: Prison vs. mandatory community intervention programs. The European Journal of Psychology Applied to Legal Context, 6(2), 69-77. https://doi.org/10.1016/j.ejpal.2014.06.003

Gonçalves, R. A., Cunha, O., \& Dias, A. R. (2011). Avaliação psicológica de agressores conjugais [Psychological assessment of marital offenders], In M. Matos, R.A. Gonçalves, \& C. Machado (Eds.), Manual de psicologia forense: Contextos, práticas e desafios [Manual of forensic psychology: Contexts, practices and chalenges] (pp. 223-245). Psiquilibrios Edições.

Graffar, M. (1956). Une méthode de classification sociale d' echantillons de population [A method of social classification of population samples]. Courier, 6, 455-459.

Hair, J. F., Black, W., Babin, B. J., \& Anderson, R. E. (2010). Multivariate data analysis: A global perspective ( $7^{\mathrm{a}}$ ed.). Pearson.

Harris, J. A. (1995). Confirmatory factor analysis of the Aggression Questionnaire. Behavior, Research, and Theory, 33(8), 991-993. https://doi.org/10.1016/0005-7967(95)00038-Y

Harris, J. A. (1997). A further evaluation of the Aggression Questionnaire: Issues of validity and reliability. Behaviour, Research and Therapy, 35(11), 1047-1053. https://doi.org/10.1016/s0005-7967(97)00064-8

Helfritz, L. E., Stanford, M. S., Conklin, S. M., Greve, K. W., Villemarette-Pittman, N. R., \& Houston, R. J. (2006). Usefulness of self-report instruments in assessing men accused of domestic violence. The Psychological Record, 56(2), 171-180. https://doi.org/10.1007/BF03395542 
Horn, J., \& McArdle, J. (1992). A practical and theoretical guide to measurement invariance in aging research. Experimental Aging Research, 18(3-4), 117-144. https://doi.org/10.1080/03610739208253916

Hornsveld, R. H. J., Muris, P., Kraaimaat, F. W., \& Meesters, C. (2009). Psychometric properties of the Aggression Questionnaire in Dutch violent forensic psychiatric patients and secondary vocational students. Assessment, 16(2), 181-192. https://doi.org/10.1177/1073191108325894

Kolla, N. J., Meyer, J. H., Bagby, R. M., \& Brijmohan, A. (2016). Trait anger, physical aggression, and violent offending in antisocial and borderline personality disorders. Journal of Forensic Sciences, 62(1). 137-141. https://doi.org/10.1111/1556-4029.13234

Machado, C., Goncalves, M. M., \& Matos, M. (2007). Manual do Inventário de Violência Conjugal (I.V.C.) [Manual of the attitudes toward marital violence scale (ECVC) and of the marital violence inventory (IVC)]. Psiquilibrios Edições.

Marôco, J. (2014). Análise de equações estruturais. Fundamentos teóricos. Software \& aplicações [Structural equations analysis: Theoretical fundamentals. Software \& applications]. Report Number.

Martin, S., Zabala, C., Del-Monte, J., Graziani, P., Aizpurua, E., Barry, T. J., \& Ricarte, J. (2019). Examining the relationship between impulsivity, aggression, and recidivism for prisoners with antisocial personality disorder. Aggression and Violent Behavior, 49, Article 101314. https://doi.org/10.1016/j.avb.2019.07.009

Maxwell, J. (2007). Development and preliminary validation of a Chinese version of the BussPerry Aggression Questionnaire in a population of Hong Kong Chinese. Journal of Personality Assessment, 88(3), 284-294. https://doi.org/10.1080/00223890701317004 
Morales-Vives, F., Codorniu-Raga, M. J., \& Vigil-Colet, A. (2005). Características psicométricas de las versions reducidas del cuestionario de agresividade de Buss y Perry [Psychometric characteristics of reduced versions of the Aggressiveness Questionnaire of Buss and Perry]. Psicothema, 17(1), 96-100.

Morren, M., \& Meesters, C. (2002). Validation of the Dutch version of the Aggression Questionnaire in adolescent male offenders. Aggressive Behavior, 28(2), 87-96. $\underline{\text { https://doi.org/10.1002/ab.90010 }}$

Nakano, K. (2001). Psychometric evaluation on the Japanese adaptation of the Aggression Questionnaire. Behavioral Research Therapy, 39(7), 853-858. https://doi.org/10.1016/S0005-7967(00)00057-7

Netemeyer, R. G., Bearden, W. O., \& Sharma, S. (2003). Scaling procedures: Issues and applications. Sage.

Norlander, B., \& Eckhardt, C. (2005). Anger, hostility, and male perpetrators of intimate partner violence: A meta-analytic review. Clinical Psychology Review, 25(2), 119-152. $\underline{\text { https://doi.org/10.1016/j.cpr.2004.10.001 }}$

Pechorro, P., Barroso, R., Poiares, C., Oliveira, J. P., \& Torrealday, O. (2015). Validation of the Buss-Perry aggression questionnaire-short form among Portuguese juvenile delinquents. International Journal of Law and Psychiatry, 44, 75-80.

$\underline{\text { https://doi.org/10.1016/j.ijlp.2015.08.033 }}$

Pettersen, C., Nunes, K. L., \& Cortoni, F. (2016). Does the factor structure of the aggression questionnaire hold for sexual offenders? Criminal Justice and Behavior, 43(6), 811-829. $\underline{\text { https://doi.org/10.1177/0093854815618692 }}$ 
Pettersen, C., Nunes,K. L., \& Cortoni, F. (2018). The factor structure of the aggression questionnaire with violent offenders. International Journal of Offender Therapy and Comparative Criminology, 62(7), 1888-1905. https://doi.org/10.1177/0306624X17691242

Prochazka, H., \& Agren, H. (2001). Aggression in the Swedish population measured with a new self-rating inventory: The Aggression Questionnaire-revised Swedish version (AQ-RSV). Nordic Journal of Psychiatry, 55(1), 17-24. https://doi.org/10.1080/080394801750093661

Ramirez, J. M., Andreu, J. M., \& Fujihara, T. (2001). Cultural and sex diferences in aggression: A comparison between Japanese and Spanish students using two different inventories. Aggressive Behavior, 27(4), 313-322. https://doi.org/10.1002/ab.1014

Redondo, N., Peña, M. E., Graña, J. L., \& Andreu, J. M. (2017). Psychometric properties of the aggression questionnaire: A replication in a sample of partner-assaultive men in psychological treatment. Psicothema, 29(4), 584-589. https://doi.org/10.7334/psicothema2016.390

Rubio-Garay, F., Carrasco, M. A., \& Amor, P. J. (2016). Aggression, anger and hostility: Evaluation of moral disengagement as a mediational process. Scandinavian Journal of Psychology, 57(2), 129-135. https://doi.org/10.1111/sjop.12270

Ruddle, A., Pina, A., \& Vasquez, E. (2017). Domestic violence offending behaviors: A review of the literature examining childhood exposure, implicit theories, trait aggression and anger rumination as predictive factors. Aggression and Violent Behavior, 34, 154-165. https://doi.org/10.1016/j.avb.2017.01.016

Schumacher, J. A., Feldbau-Kohn, S., Slep, A. M. S., \& Heyman, R. E. (2001). Risk factors for male-to-female partner physical abuse. Aggression and Violent Behavior, 6(2-3), 281-352. https://doi.org/10.1016/S1359-1789(00)00027-6 
Serin, R. C., Gobeil, R., \& Preston, D. L. (2009). Evaluation of persistently violent offender treatment programs. International Journal of Offender Therapy and Comparative Criminology, 53(1), 57-73. https://doi.org/10.1177/0306624X07313985

Simões, A. (1993). São os homens mais agressivos que as mulheres? [Are men more aggressive than women?]. Revista Portuguesa de Pedagogia, XXVII(3), 387-404.

Stith, S. M., Smith, D. B., Penn, C., Ward, D., \& Tritt, D. (2004). Intimate partner physical abuse perpetration and victimization risk factors: A meta-analytic review. Aggression and Violent Behavior, 10(1), 65-98. https://doi.org/10.1016/j.avb.2003.09.001

Valdivia-Peralta, M., Fonseca-Pedrero, E., González-Bravo, L., \& Lemos- Giráldez, S. (2014). Psychometric properties of the AQ Aggression Scale in Chilean students. Psicothema, 26(1), 39-46. https://doi.org/10.7334/psicothema2013.84

van der Put, C. E., Stams, G. J. J. M., Hoeve, M., Dekovic, M., Spanjaard, H. J. M., van der Laan, P. H., \& Barnoski, R. P. (2012). Changes in the relative importance of dynamic risk factors for reoffending during adolescence. International Journal of Offender Therapy and Comparative Criminology, 56(2), 296-316. https://doi.org/10.1177/0306624X11398462

Vitoratou, S., Ntzoufras, I., Smyrnis, N., \& Stefanis, N. C. (2009). Factorial composition of the aggression questionnaire: A multi-sample study in Greek adults. Psychiatry Research, 168(1), 32-39. https://doi.org/10.1016/j.psychres.2008.01.016

Williams, T. Y., Boyd, J. C., Cascardi, M. A., \& Poythress, N. (1996). Factor structure and convergent validity of the Aggression Questionnaire in an offender population.

Psychological Assessment, 8(4), 398-403. https://doi.org/10.1037/1040-3590.8.4.398 
Table 1.

Forensic Sample Sociodemographic Characterization

\begin{tabular}{lcc}
\hline & $N$ & $\%$ \\
\hline Marital Status & 38 & 13.6 \\
Single & 118 & 42.3 \\
Married/cohabitation & 100 & 35.8 \\
Divorced/Separated & 23 & 8.2 \\
Widow & & \\
\hline Educational Level & 8 & 2.9 \\
Less than 4 years & 103 & 36.9 \\
4 years & 87 & 31.2 \\
6 years & 40 & 14.3 \\
9 years & 32 & 11.5 \\
12 years & 9 & 2.9 \\
13 years or more & & \\
\hline Professional Status & 163 & 58.6 \\
Employed & 82 & 29.6 \\
Unemployed & 30 & 10.8 \\
Retired & 2 & 0.7 \\
Student & & \\
\hline Socioeconomic level & 45 & 16.2 \\
Low & 131 & 47.1 \\
Medium-Low & 73 & 26.3 \\
Medium & 24 & 8.6 \\
Medium-High & 5 & 1.8 \\
High & & \\
\hline & & \\
\hline
\end{tabular}


Table 2.

BPAQ, BSI, IVC and BPAQ-SF Means, Standard Deviations, and Range

\begin{tabular}{lcccc}
\hline & Mean & SD & Min & Max \\
\hline BPAQ Total & 61.92 & 15.58 & 34 & 113 \\
BPAQ Physical Aggression & 17.09 & 5.48 & 9 & 35 \\
BPAQAQ Verbal Aggression & 12.15 & 3.58 & 5 & 24 \\
BPAQ Anger & 14.15 & 5.23 & 7 & 30 \\
BPAQ Hostility & 18.52 & 5.69 & 8 & 38 \\
\hline BSI Anxiety & 0.71 & 0.68 & 0 & 3.83 \\
BSI Hostility & 0.53 & 0.62 & 0 & 2.80 \\
BSI Paranoid Ideation & 1.31 & 0.79 & 0 & 3.40 \\
\hline IVC Total & 11.90 & 7.66 & 0 & 34 \\
IVC Physical & 6.54 & 5.43 & 0 & 22 \\
IVC Psychological & 5.89 & 3.45 & 0 & 16 \\
\hline BPAQ-SF Total & 23.96 & 7.41 & 12 & 51 \\
BPAQ-SF physical aggression & 5.21 & 2.32 & 3 & 14 \\
BPAQ-SF verbal aggression & 5.20 & 2.28 & 3 & 15 \\
BPAQ-SF Anger & 6.09 & 2.66 & 3 & 15 \\
BPAQ-SF Hostility & 7.45 & 2.73 & 3 & 15 \\
\hline NOte. BPAQ - Buss-Perry Aggression & & & 3 & \\
\hline
\end{tabular}

Note. BPAQ - Buss-Perry Aggression Questionnaire; BSI - Brief Symptom Inventory; IVC Marital Violence Inventory; BPAQ-SF - Buss-Perry Aggression Questionnaire - Short Form. 
Table 3.

Confirmatory Factor Analysis for BPAQ and BPAQ-SF

\begin{tabular}{llllll}
\hline Model & $x^{2} / \mathrm{df}$ & CFI & TLI & RMSEA (90\% CI) & AIC \\
\hline BPAQ & 2.324 & .74 & .72 & $.069[.063-.075]$ & 989.052 \\
BPAQ-SF & 3.653 & .93 & .91 & $.065[.055-.075]$ & 235.332 \\
\hline
\end{tabular}

Note. BPAQ - Buss-Perry Aggression Questionnaire; BPAQ-SF - Buss-Perry Aggression

Questionnaire - Short Form; $\chi 2$ - Chi-Square; df - degrees of freedom; CFI - Comparative Fit Index; TLI - Tucker-Lewis Index; RMSEA - Root Mean Square Error of Approximation; AIC Akaike Information Criterion. 
Table 4

Standardized Factor Loadings and Item-Total Pearson Correlations of the BPAQ-SF

\begin{tabular}{lcc}
\hline Items & Loadings & ITC \\
\hline Physical Aggression & .533 & .499 \\
I have threatened people I know. & .609 & .593 \\
Given enough provocation, I may hit another person. & .560 & .496 \\
There are people who pushed me so far that we came to blows. & .483 & .508 \\
\hline Verbal Aggression & .576 & .521 \\
I can't help getting into arguments when people disagree with me. & .531 & .492 \\
I often find myself disagreeing with people. & & \\
My friends say that I'm somewhat argumentative. & .533 & .627 \\
\hline Anger & .595 & .589 \\
I flare up quickly but get over it quickly. & .575 & .549 \\
I have trouble controlling my temper. & .557 & .564 \\
Sometimes I fly off the handle for no good reason. & .500 & .508 \\
\hline Hostility & .560 & .529 \\
I wonder why sometimes I feel so bitter about things. & & \\
At times I feel I have gotten a raw deal out of life. & & \\
Other people always seem to get the breaks. & & \\
\hline
\end{tabular}


Table 5.

Correlations between BPAQ-SF Total and Scales, BSI Anxiety, Hostility, and Paranoid Ideation and IVC Total and Scales

$\begin{array}{lllllllll}1 & 2 & 3 & 4 & 5 & 6 & 7 & 8 & 9\end{array}$

\section{BPAQ-SF Physical}

Aggression

2. BPAQ-SF Verbal

Aggression

3. BPAQ-SF Anger

4. BPAQ-SF Hostility

5. BPAQ-SF Total

6. BSI Hostility

7. BSI Anxiety

8. BSI Paranoid Ideation

9. IVC Physical

10. IVC Psychological

11. IVC Total

Note. BPAQ

Inventory.

$* p<.005 ; * * p<.01 ; * * * p<.001$.
$.346 * * * \quad 1$

$.472 * * * \quad .471 * * * \quad 1$

$353 * * * \quad .326 * * * \quad .421 * * * \quad 1$

$719 * * * \quad .705 * * * \quad .806 * * * \quad .730 * * *$

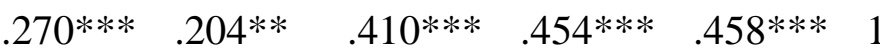

$\begin{array}{lllllll}.458 * * * & .421 * * * & .559 * * * & .363 * * * & .604 * * * & .526 * * * & 1\end{array}$

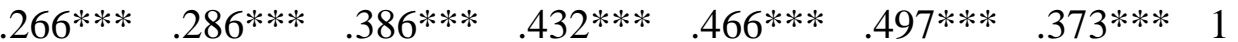

$\begin{array}{llllllll}.144 * & -.022 & .096 & .183 * * & .140 * & .008 & .005 & .121\end{array}$

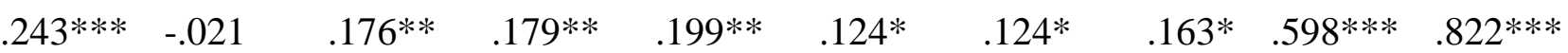

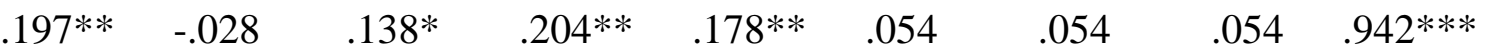

. 
Table 6.

Tests of Measurement Invariance of the BPAQ-SF

\begin{tabular}{llllclll}
\hline & & \multicolumn{1}{c}{$\boldsymbol{X}^{\mathbf{2}}$} & $\mathbf{d f}$ & $\mathbf{R M S E A}$ & CFI & TLI & $\Delta$ CFI \\
\hline Sample & Configural invariance & 206.997 & 88 & $.039[.032-.045]$ & .95 & .93 & \\
type & Metric invariance & 223.524 & 96 & $.038[.032-.045]$ & .95 & .93 & .006 \\
& Scalar invariance & 302.510 & 114 & $.037[.031-.043]$ & .95 & .93 & .01 \\
\hline Sentence & Configural invariance & 110.776 & 82 & $.036[.015-.052]$ & .95 & .92 & \\
type & Metric invariance & 127.937 & 90 & $.039[.022-.054]$ & .93 & .90 & .01 \\
& Scalar invariance & 148.060 & 100 & $.042[.026-.055]$ & .92 & .90 & .01 \\
\hline
\end{tabular}

Note. BPAQ-SF - Buss-Perry Aggression Questionnaire - Short Form. $\chi^{2}$ - Chi-Square; df degrees of freedom; CFI - Comparative Fit Index; TLI - Tucker-Lewis Index; RMSEA - Root Mean Square Error of Approximation. 
Table 7.

Descriptive Statistics and ANOVAS for the BPAQ-SF and its Scales

\begin{tabular}{lcccc}
\hline & $\boldsymbol{M}(\boldsymbol{S D})$ & $\boldsymbol{M}(\boldsymbol{S D})$ & $\boldsymbol{F}(\boldsymbol{p}$ value $)$ & $\begin{array}{c}\text { Partial Eta } \\
\text { Squared }\end{array}$ \\
\hline Sample type & Forensic & Community & & \\
BPAQ-SF Total & $23.96(6.83)$ & $24.13(6.83)$ & $3.149(=.043)$ & .007 \\
BPAQ-SF Physical Aggression & $5.21(2.33)$ & $4.74(2.22)$ & $8.920(\leq .001)$ & .019 \\
BPAQ-SF Verbal Aggression & $5.20(2.28)$ & $6.23(1.98)$ & $26.492(\leq .001)$ & .055 \\
BPAQ-SF Anger & $6.09(2.66)$ & $6.49(2.39)$ & $3.356(.035)$ & .007 \\
BPAQ-SF Hostility & $7.45(2.74)$ & $6.67(2.51)$ & $9.345(\leq .001)$ & .020 \\
\hline Sentence type & Prison & Community & & \\
BPAQ-SF Total & $23.83(7.83)$ & $24.09(7.01)$ & $.083(=.774)$ & - \\
BPAQ-SF Physical Aggression & $5.13(2.21)$ & $5.30(2.45)$ & $.375(=.541)$ & - \\
BPAQ-SF Verbal Aggression & $5.28(2.59)$ & $5.12(1.93)$ & $.370(=.544)$ & - \\
BPAQ-SF Anger & $5.85(2.68)$ & $6.34(2.63)$ & $2.380(=.124)$ & - \\
BPAQ-SF Hostility & $7.57(2.90)$ & $7.33(2.56)$ & $.531(=.467)$ & - \\
\hline Note. BPAQ-SF - Buss-Perry Aggr)
\end{tabular}

Note. BPAQ-SF - Buss-Perry Aggression Questionnaire - Short Form. 